\title{
Exploring Potential Participation of Vietnam in the Carbon Market
}

\author{
Mai Kim Lien, Nguyen Dieu Huyen, Nguyen Thanh Cong, Nguyen Van Minh \\ Department of Climate Change, Ministry of Natural Resource and Environment, Hanoi, Vietnam \\ Email:nguyendieuhuyen.dcc@gmail.com
}

How to cite this paper: Lien, M. K., Huyen, N. D., Cong, N. T., \& Minh, N. V. (2020) Exploring Potential Participation of Vietnam in the Carbon Market. Low Carbon Economy, 11, 25-43.

https://doi.org/10.4236/lce.2020.112002

Received: April 30, 2020

Accepted: June 27, 2020

Published: June 30, 2020

Copyright (C) 2020 by author(s) and Scientific Research Publishing Inc. This work is licensed under the Creative Commons Attribution International License (CC BY 4.0).

http://creativecommons.org/licenses/by/4.0/ c) (i) Open Access

\begin{abstract}
Currently, the development of the carbon market is considered as an urgent requirement because it contributes to creating certain economic values and protecting the environment and sustainable development of a country. In addition, this instrument can also enhance diplomatic relations through scientific, technological and financial investments among countries all over the world. Vietnam is assessed as having potential to reduce its greenhouse gas (GHG) emissions by $9 \%$ compared to the Business-As-Usual scenario by 2030 using domestic resources (equivalent to 83.9 million tons of $\mathrm{CO}_{2} \mathrm{eq}$ ). The above-mentioned $9 \%$ contribution can be increased by up to $27 \%$ (equivalent to 250.8 million tons of $\mathrm{CO}_{2} \mathrm{eq}$ ) if the country can receive the international support through bilateral and multilateral cooperation as well as the implementation of new mechanisms under the Paris Agreement. The paper gives an overview of a number of domestic carbon markets in some countries and assesses the potential for developing Vietnam's carbon market.
\end{abstract}

\section{Keywords}

Vietnam, Carbon Market, Kyoto Protocol, Paris Agreement

\section{Introduction}

The Paris Agreement on Climate Change was adopted by the states in COP 21 as the first global legal document regulating responsive to climate change. The focus of the Paris Agreement is the introduction of regulations concerning the responsibility of developing and implementing a Nationally Determined Contribution (NDC) of each of the Parties to the United Nations Convention Framework on Climate Change (UNFCCC). So far, the Agreement has been ratified by 189 Parties of 197 Parties to the Convention and officially entered into force on $4^{\text {th }}$ November 2016.

The current urgent priority for countries is to implement NDCs as committed with the UNFCCC. GHG emission reduction can be conducted through two tools: 
command-and-control regulations and carbon pricing tools. Examples for command-and-control instruments include law on climate change, emission quotas and technology standards. In practice, the implementation of command and control regulations can be costly and challenging as GHG come from a variety of sources of emissions and activities. Therefore, the carbon pricing tools or the market-based approach, which sets the price for GHG emissions, is quite attractive as it encourages the lowest-cost reduction of emissions and promotes the introduction of new initiatives to reduce carbon emissions (Marron, Toder, \& Austin, 2015). Out of 195 Parties, about 100 Parties, accounting for 58\% of global GHG emissions, are considering or planning to use a carbon pricing tool to achieve GHG emission reduction targets.

The carbon pricing tools include the carbon tax and emissions trading system, in which each tool has its advantages and disadvantages, and the way it or both can be used depending on the actual situation in one country/region. Carbon trading is a market-based instrument to mitigate climate change and it is implemented under two forms: cap-and-trade and carbon offsets. The idea of carbon trading was emerged firstly as a form of "pollution trading" in the USA in 1960s. Later, it was formalized by the 1997 Kyoto Protocol and was proposed three flexible mechanisms including Emissions Trading (ET), Joint Implementation (JI) and Clean Development Mechanism (CDM) (Böhm \& Dabhi, 2009). In 2003, the European Union Greenhouse Gas Emission Trading System (EU ETS) was introduced by the Directive 2003/87/EC and was entered into force (EUROPA, 2010). The creation of carbon market aims at cutting down the maximum emissions at the lowest cost and is based on an assumption that the emission reduction is technically the same anywhere on Earth as long as it happens (Böhm \& Dabhi, 2009).

Since the Kyoto Protocol has been adopted, carbon markets have significantly developed in European countries, the Americas and Asia, with two main types of markets, the mandatory carbon market and the voluntary carbon market. The former type is the market in which carbon trade is based on the commitments of states in the UNFCCC to achieve the goal of reducing GHG emissions. This market is mandatory and is mainly for Clean Development Mechanism (CDM) or Co-Implementation (JI) projects. In addition to the regulated market controlled by EU ETS and the Kyoto Protocol, the latter type has emerged for both cap-and-trade and carbon offsets on the basis of bilateral or multilateral cooperation agreements between groups, organization, companies or countries. For examples, Japan's Joint Credit Mechanism (JCM) and Reducing Emission from Deforestation, forest Degradation, forest carbon conservation and enhancement and sustainable management of forests (REDD+) (World Bank, 2016) are voluntary market for carbon offsets.

According to a World Bank (2016) report, about 40 countries and more than 20 cities, states and regions (accounting for nearly a quarter of the total global GHG emissions) have pricing on carbon. Carbon tax, with the quota system and managed emission rights trading comprises of $7 \mathrm{GtCO}_{2} \mathrm{e}$ (equivalent to $13 \%$ of global 
GHG emissions, of which a management carbon tax of $4 \%$ and a quota and purchase system sell regulated emissions rights by $8 \%$. To date, there are 21 countries (excluding Australia because they abolished carbon taxes in 2014), 3 Canadian states (British Colombia, Alberta and Quebec) and 1 city in the US (Boulder) adopt the legal basis for the imposition of carbon taxes.

A short description of a number of carbon pricing instruments is shown below. They will play an important role in the implementation of the Paris Agreement and the NDC.

\subsection{Cap-and-Trade System}

According to the principle of "cap-and-trade" or permit trading, the government will set an upper limit of carbon emission (so-called "a cap") for companies, and then allocate them a number of licenses to pollute "carbon permits". The companies that fail to meet their cap can purchase credits from those having a surplus (Böhm \& Dabhi, 2009).

\subsubsection{Regulated Market}

The regulated market under the "cap-and-trade" scheme is the EU ETS which is the world's largest multi-national emissions trading system which has been in operation since 2005 to respond to climate change and is an important pillar of Europe's climate policy. The goal of the EU ETS is to reduce GHG emissions by $20 \%$ by $2020,40 \%$ by 2020 and $80 \%$ - $95 \%$ by 2050 (compared to 1990 levels). EU-ETS was the main driver of the world carbon market in the period 2008-2012. By January 2013, more than 11,000 factories, power plants and other facilities in 31 countries, including 28 European countries, Iceland, Norway and Liechtenstein participated in the EU ETS. As a result, about $45 \%$ of Europe's GHG emissions are managed by the EU-ETS. EU-ETS emission limits are increasing, especially in phase II (EC, 2016).

\subsubsection{Voluntary Market}

In addition to EU ETS, a number of voluntary cap-and-trade systems have been established in a number of countries such as the USA, Australia, and China.

Although the United States has not ratified the Kyoto Protocol, some regions in the United States have developed their own GHG emission trading programs, particularly the Regional GHG Initiative (RGGI), Western Climate Initiative (WCI) and the Midwestern Region GHG Reduction Treaty (MGGRA).

In three regions in the United States, the Regional GHG Initiative (RGGI) is the first market-based mechanism which was established in 2005 to reduce GHG emissions to limit and reduce $\mathrm{CO}_{2}$ emissions in the energy sector in the Eastern states. This program focuses on large generators with nearly $100 \%$ of quotas for sale (Richard, William, \& Daniel, 2012). According to the 2012 Program Assessment, the states of RGGI have set a limit of 91 million tons of $\mathrm{CO}_{2}$ eq in 2014. RGGI's $\mathrm{CO}_{2}$ limit decreases by $2.5 \%$ per year in the period of 2015-2020. RGGI's $\mathrm{CO}_{2}$ limit represents the regional budget for $\mathrm{CO}_{2}$ emission reduction in the en- 
ergy sector. The second US emissions trading system started in California in 2013. The Western Climate Initiative (WCI) was launched by the states of Arizona, California, New Mexico, Oregon, and Washington in 2007, then added Utah and Montana as well as British Columbia, Ontario, Manitoba and Quebec. However, only California operates emissions trading program. California's program initially focused on the power generation and major industrial resources sectors, accounting for about $37 \%$ of the state's GHG emissions and expanded coverage to $85 \%$ by 2015 , including the fuel sector in transportation (Richard, William, \& Daniel, 2012). The Midwestern GHG Reduction Treaty (MGGRA) was signed in 2007. MGGRA focuses on the power sector, the major emitting industrial entities and fuel distributors for transportation in which quotas are allocated for free. Although MGGRA has achieved certain successes, the MGGRA ended in early 2011 due to the change of the political apparatus and the shift of economic priorities.

In Australia, the New South Wales GHG emission reduction system (NSW GGAS) is a mandatory emissions trading system in the electricity sector. It was established to reduce GHG emissions in New South Wales in January 2003. In order to encourage implementation, the NSW GGAS has introduced fines for members who exceed emissions. The fine in 2010 was $\$ 13.95 /$ ton $\mathrm{CO}_{2}$ e. This penalty increased to AUD 1 per year until 2013.

In 2013, China launched 7 pilot emission trading programs, of which Shanghai's program was put into operation from $18^{\text {th }}$ June 2013 . Under this pilot program, 635 companies in Shanghai in 23 industries (emitting 38\% of the city's total emissions) are responsible for $6.68 \%$ of carbon intensity (tons of $\mathrm{CO}_{2} /$ product) in average from 2013 to 2015. In addition to exchanging quota permits, companies can also buy and sell Chinese emission reduction certificates (CCERs) issued by the National Development and Reform Commission. Currently, China is still testing seven carbon markets with 2000 factories, accounting for 120 million tons of annual carbon limit in total. China launched its national ETS politically in December 2017 based on its experience of successfully piloting carbon markets in seven regions. The ETS is expected to regulate about 1700 companies from the power sector (including combined heat and power, as well as captive power plants of other sectors), which emit more than 26,000 tonnes GHG or consume more than 10,000 TCE (Tons of Standard Coal Equivalent) per year (ICAP, 2020).

The permit trading receives both advocates and oppositions. On one hand, permit trading is considered to reduce emissions at least cost (Ellerman, Convery, \& de Perthuis, 2010) and stimulate eco-friendly innovations in industries. It is also more effective than taxation as it controls the amount of emissions and provides financial incentives. On the other hand, permit trading is supposed to defer the investment into low-carbon technology (Smith, 2007) and profited big polluters owing to their high emission allowance (WWF, 2008; Böhm \& Dabhi, 2009). The so-called "hot air" problem of the former Soviet Union and Eastern Europe is also controversial when emissions reductions are stemmed from economic transition, not from efforts to cut down emissions (Soroos, 2001). Finally, there are several 
barriers to the effective implementation of the cap-and-trade system such as industrial lobbying and opaque exchange-based emissions market.

\subsection{Carbon Offsets}

\subsubsection{Regulated Market}

If governments, companies and individuals do not want to reduce emissions by themselves, they can offset their emissions by investing in "emissions-saving projects" to get carbon credits. The so-called CDM and JI projects are being implemented in developing countries and "economies in transition". In 2005, a scheme on Reducing Emissions from Deforestation in Developing Countries (REDD) was proposed in COP 11. It required the industrialized countries to pay money for the underprivileged ones for their efforts in reducing the deforestation rate (Böhm \& Dabhi, 2009). According to UNEP Riso, the forecasted demand for carbon credits in the period 2013-2020 is $3 \mathrm{Gt} \mathrm{CO}_{2} \mathrm{eq}$, mainly from Europe (1.5 Gt $\mathrm{CO}_{2} \mathrm{eq}$ ), Australia, New Zealand and California. The need for carbon credits is much lower than the forecast for carbon credit $\left(7 \mathrm{Gt} \mathrm{CO}_{2} \mathrm{eq}\right)$. It, therefore, causes a decrease of the price of CERas consequently, by $12^{\text {nd }}$ December 2012, the price of CER was only $0.31 \mathrm{USD} / \mathrm{CER}$.

\subsubsection{Voluntary Market}

Parallel to the market legitimated by the UNFCCC, the voluntary carbon offset market has emerged and is not compulsory to reach any binding target. Any corporations, NGOs and individuals who want to "neutralize" their emissions can pay money for some companies like Chicago Climate Exchange and then these companies will invest into "green projects". While the regulated carbon market has not achieved the expected results and is becoming increasingly quiet in the context of climate change negotiations around the world, the voluntary carbon market is growing and being formed and implemented in many countries such as Australia, New Zealand, USA, China, Korea, and Thailand.

The voluntary emissions trading market is regulated by different sets of standards depending on buyer's requirements. Verified Carbon Standard (VCS) is in common use now. The transaction unit in this suite of standards is VCU (Verified Carbon Unit). The dominant type of emission reduction certificate in this market must be mentioned as RMU (unit that removes GHG emissions based on activities of using and changing land use such as reforestation). Voluntary carbon operates under a number of separate mechanisms depending on the country where it is applied.

According to the State of the Voluntary Carbon Markets 2019, the voluntary carbon market has grown rapidly in 2008-2012 period, in which average year of transactions equivalent to 115.2 million $\mathrm{tCO}_{2} \mathrm{eq}$ for a total market value of $\$ 570.2$ million per year. Similar to the decline in the regulated carbon market, the voluntary carbon market also declines starting in 2013. In 2013-2018 period, average year of transactions equivalent to 73.0 million $\mathrm{tCO}_{2} \mathrm{eq}$ for a total market value of \$259.4 million per year (Ecosystem Marketplace, 2019). 
The majority of VER projects are of unproven quality due to the lack of an independent quality control body which is available in the CDM system. In other cases, the project developers will compare their projects with certain standards, such as the Voluntary Carbon Standard (VCS), the Vivo Plan Standard and Social Carbon. Among the standards applied to VER projects, the Gold Standard is considered as the best and has been applied to projects outside the CDM system.

Just like "cap-and-trade" system, there are both supporting ideas and disagreements about the carbon offsets. CDM in theory can bring back cost-effective reduction and sustainable development in the Majority World. However, the underlying problem of all offsets projects is the baseline and environmental additionality (Smith, 2007; Bumpus, Murray, \& Liverman, 2009). It is uncertain to determine the business-as-usual baseline and criteria for environmental additionality and hence emissions may increase due to the exaggeration of the actual baseline and the over-allocation of Certified Emission Reductions (CERs) (Woerdman, 2000; Pearson \& Shao Loong, 2003; Michaelowa, 2005; Bumpus, Murray, \& Liverman, 2009; Boyd et al., 2007; Schneider, 2007) and the problem of "future value accounting" (Smith, 2007).

\section{Materials and Methods}

\subsection{Approach}

This research is implemented based on reviewing previous research related to factors that affecting the development of carbon market in Vietnam, including 1) supporting international and national climate policies; 2) national mitigation potential and 3) current experience in carbon market. Based on the review, the paper scored each factor then assessed Vietnam's potential to participate in the carbon market based on the total scores for cap-and-trade and carbon offset under both regulated and voluntary markets. Information from desk study and expert consultation will be important input for the assessment.

The approach for conducting this study includes 4 steps:

Step 1: Reviewing the international and national policies regulating/supporting for the development and operation of carbon market and measurement, reporting and verification (MRV) internationally and in Vietnam, respectively. If the supporting policies are adequate, the potential to participate in the carbon market will be higher;

Step 2: Reviewing Vietnam's updated Nationally Determined Contribution to assess the mitigation potential of the country and sectors, including energy, IPPU, agriculture, LULUCF and waste. The sector with higher mitigation potential will have higher potential to participate into the carbon market;

Step 3: Reviewing Vietnam's current experience in carbon market. The sectors which have preparedness activities or already are involved in CDM or voluntary carbon projects will have more potential to participate in the carbon market in future;

Step 4: Scoring the factors affecting the potential to participate in the carbon 
market based on expert consultation.

\subsection{Method and Data}

Data used in this research was collected from the Vietnam's NDC update technical report, including (1) Mitigation actions: Energy (39 options); IPPU (4 options); Agriculture (15 options); LULUCF (12 options); and, Waste ( 9 options). In addition, information on carbon market supporting policies and Vietnam's current experience in carbon market was collected from literature review. In this paper, three research methods were applied, including: 1) desk study; 2) multi-criteria analysis (MCA) and 3) expert consultation.

\subsubsection{Desk Study}

This method was applied on the basis of inheriting, analyzing and synthesizing documents, and relevant information, from which to evaluate them according to requirements of research purposes.

This method is conducted on the basis of collecting documents related to identifying potentials for the development of carbon markets in Vietnam, including policy system to mitigate GHG emissions in Vietnam, particularly laws, strategies, plans, projects, and policies to support the development of the carbon market in Vietnam. In this part, the institutional and policy advantages for the carbon market formation in Vietnam will be analyzed and synthesized.

\subsubsection{Multi-Criteria Analysis (MCA)}

The matrix analysis method is used to determine the most potential market-based instruments that should be applied in Vietnam. Vietnam's potential to participate into carbon market, including cap-and-trade and carbon offsets, was assessed against three criteria: 1) supporting international and national climate policies; 2) national mitigation potential and 3) current experience in carbon market. The total score for each instrument will reflect Vietnam's potential to participate into carbon market.

\subsubsection{Expert Consultation}

Currently, in general research, the expert method is considered an important and effective method to mobilize the experience and understanding of the interdisciplinary team of experts in the research field. Therefore, the results will be highly practical and scientific, avoiding duplication with existing studies, and inheriting the research achievements. In addition to literature review, this paper will also conduct scoring each criterion-based consultation with experts who have deeply knowledge in market-based instruments and climate policies.

\section{Results and Discussion}

Based on desk study, MCA and expert consultation, each factor affecting the development of carbon market in Vietnam is scored from 1 to 5 , of which 1 is the 
lowest and 5 is the highest (Table 1). The detailed explanation for scores of each factor is presented in the sections below.

\subsection{Supporting Policies for the Development of Carbon Market}

\subsubsection{International Regulations}

\section{1) Post-Kyoto Regime}

As can be seen, Kyoto investor phase 1 has set a premise for the development of the international carbon market. However, while the carbon market continues to operate, the future of the Kyoto Protocol as a framework for GHG emission reduction is uncertain (Richard, William, \& Daniel, 2012). At the $18^{\text {th }}$ Conference of the Parties to the United Nations Framework Convention on Climate Change (COP18), the Parties agreed that a second committing period of the Kyoto investor will start from $1^{\text {st }}$ January 2013 and ends December 31, 2020. The goal of this phase is to reduce at least $18 \%$ of total GHG emissions below 1990 levels between 2013 and 2020. Nitrogen trifluoride $\left(\mathrm{NF}_{3}\right)$ will start to be controlled from the second commitment period of Kyoto investor. Kyoto Phase 2 is expected to take effect from $1^{\text {st }}$ January 2013 when at least 144 countries ratify to

Table 1. Assessment of Vietnam's potential to participate in the carbon market.

\begin{tabular}{|c|c|c|c|c|}
\hline & \multicolumn{2}{|c|}{ Regulated market } & \multicolumn{2}{|c|}{ Voluntary carbon market } \\
\hline & Cap-and-trade & Carbon offset & Cap-and-trade & Carbon offset \\
\hline \multicolumn{5}{|l|}{ Supporting policies } \\
\hline International policies & $\begin{array}{c}5 \\
(\text { EU ETS) }\end{array}$ & $\begin{array}{c}2 \\
\text { (no clear provision on } \\
\text { carbon offset in Paris } \\
\text { Agreement) }\end{array}$ & 0 & 0 \\
\hline National policies & $\begin{array}{c}0 \\
\text { (no cap-and-trade in } \\
\text { Vietnam at present) }\end{array}$ & $\begin{array}{c}4 \\
\text { (existing legal basis for } \\
\text { CDM; MRV needs being } \\
\text { further developed) }\end{array}$ & 0 & 0 \\
\hline & 4 & 2 & 4 & 2 \\
\hline & (only carbon credi & exceed the national mitigatic & on target will be sold to the & ational market) \\
\hline $\begin{array}{l}\text { Vietnam's current experience } \\
\text { in carbon market }\end{array}$ & $\begin{array}{c}0 \\
\text { (no cap-and-trade in } \\
\text { Vietnam at present) }\end{array}$ & $\begin{array}{c}4 \\
(\mathrm{CDM})\end{array}$ & $\begin{array}{c}0 \\
\text { (no cap-and-trade in Vi- } \\
\text { etnam at present) }\end{array}$ & $\stackrel{3}{(\mathrm{REDD}, \mathrm{JCM})}$ \\
\hline Total & 9 & 12 & 4 & 5 \\
\hline
\end{tabular}

avoid gaps in response to global climate change. However, at present only 140 countries have ratified and they are mainly developing countries. Many developed countries have withdrawn from Kyoto investor phase 2 such as Canada, Russia and Japan while the US has never approved Kyoto investor (Richard, William, \& Daniel, 2012).

The different commitments between countries have created an uncertain picture 
for the way ahead. However, a variety of governments have developed market-based programs to reduce greenhouse gas emissions within or outside of the Kyoto Protocol.

\section{2) Paris Agreement}

The Paris Agreement on Climate Change was adopted by the states in COP 21 as the first global legal document regulating responsive to climate change. The focus of the Paris Agreement is the introduction of regulations concerning the responsibility of developing and implementing an NDC of each Parties to the UNFCCC. So far, the Agreement has been ratified by 189 Parties of 197 Parties to the Convention and officially entered into force on $4^{\text {th }}$ November 2016 . Out of 197 Parties, about 100 Parties, accounting for 58\% of global GHG emissions, are considering or planning to use a carbon pricing tool to achieve GHG emission reduction targets.

The market-based approach in this new context faces many challenges. First, the Paris Agreement does not cover carbon trading mechanisms in the text. Instead, the Agreement includes the issue of "market" in Article 6, which deals with "voluntary cooperation" between the Parties to achieve the NDC. Under Article 6, if the cooperation uses the international exchange of mitigation results (ITMO), a precise calculation should be used to avoid duplication. The use of ITMO is voluntary and must be authorized by the Parties to this Agreement. In addition, Article 6 also establishes an emission reduction mechanism (EMM) and supports sustainable development. As can be seen, the Parties have developed EMM and ITMO to support carbon pricing. By implementing the Paris Agreement, EMM can be facilitated cross-country credit/carbon credit trading (ITMO) (IETA, 2016; Marcu, 2016).

\subsubsection{National Policies Supporting the Development of Carbon Market} Legislation, monitoring and regulation, MRV and joint emissions compliance systems are the institutional foundations of a carbon market.

\section{1) Policies related to mitigation and carbon market}

In recent years, Vietnam has issued a number of policies, programs and plans relating to climate change:

Resolution No. 24-NQ/TW dated $3^{\text {rd }}$ June 2013 of the Central Committee of the Party, session XI, on active response to climate change, strengthening natural resources management and environmental protection has identified climate change adaptation as an opportunity to promote growth pattern transformation towards sustainable development and simultaneously to conduct adaptation and mitigation actions.

Law on Environmental Protection No. 55/2014/QH13 (National Assembly of the Socialist Republic of Vietnam, Session XIII adopted on $23^{\text {rd }}$ June 2014) with Chapter IV providing regulations on climate change response; provides statutory provisions on response to climate change, including assessing climate change mitigation and adaptation measures, managing GHG emission and regulating the roadmap and modality for participation in reducing global GHG in conformity 
with socio-economic conditions and commitments made in the international treaties to which the Socialist Republic of Vietnam is a party.

Resolution No. 08/NQ-CP dated $23^{\text {rd }}$ January 2014 by the Government issued the Government's action program to implement Resolution No. 24-NQ/TW, which stipulates that one of the key tasks of responding to climate change is to mitigate GHG emissions, while increasing the capacity of the ecosystem to absorb GHG.

Decision No. 2139/QD-TTg dated 05 ${ }^{\text {th }}$ December 2011 of the Prime Minister approving the National Strategy for Climate Change has set the overall objective as to mobilize national capacity; and to carry out simultaneously measures of climate change adaptation and GHG emissions reduction to ensure safety for people and properties for the sustainable development goals toward low-carbon economy and green growth.

Decision No. 1393/QD-TTg dated 25 ${ }^{\text {th }}$ September 2012 of the Prime Minister approving the National Strategy on Green Growth for the period of 2011-2020 with a vision to 2050 with the overall objective of achieving a low carbon economy, reduction in emissions and increase in the possibility to absorb GHG sets mandatory and important targets in socioeconomic development.

Decision No. 1775/QD-TTg dated 21 ${ }^{\text {st }}$ November 2012 of the Prime Minister approving the Plan on GHG emission management and the management of carbon credit business activities in the world market with the general target to manage GHG emissions aims to implement the UNFCCC and other international agreements in which Vietnam is a party, and at the same time take advantage of the opportunity to develop a low carbon economy with green growth.

Decision No. 2068/QD-TTg dated 25 ${ }^{\text {th }}$ November, 2015 of the Prime Minister approved Vietnam's Renewable Energy Development Strategy up to 2030 with a vision to 2050. Some key objectives of the strategy are to "reduce GHG emissions in energy activities compared to normal development with about $5 \%$ by 2020 ; $25 \%$ by 2030 and $45 \%$ by 2050 ".

Decision No. 2359/QD-TTg dated 22 ${ }^{\text {nd }}$ December 2015 of the Prime Minister approved the National Greenhouse Gas (GHG) Inventory System. The main objectives of the system include to "make biennial GHG inventories and develop national climate change reports and to submit them to the UNFCCC" and "contribute to the achievement of low carbon economy, green growth and GHG reduction targets in the NDC of Vietnam".

Resolution No. 93/NQ-CP dated $31^{\text {st }}$ October 2016 of the Government approved Paris Agreement to implement the UNFCCC. In this Resolution, the Government assigned Ministry of Natural Resources and Environment (MONRE) to preside and cooperate with concerned ministries, sectors and localities to implement and widely disseminate Paris Agreement after it enters into force.

Decision No. 2053/QD-TTg dated 28 ${ }^{\text {th }}$ October 2016 of the Prime Minister approving the Action Plan for Implementation of the Paris Agreement on climate change for the period of 2016-2020 aims to: 1) review existing regulations and develop a Decree on the roadmap and modality for GHG emission mitigation; 2) 
develop a carbon market within the country; piloting the system, policies and market tools for mitigation of GHG emissions in potential sectors; and 3) develop and implement GHG mitigation and green growth proposals in accordance with national conditions for implementation of NDC.

Vietnam ratified the UNFCCC on $16^{\text {th }}$ November 1994, the Kyoto Protocol on $25^{\text {th }}$ September 2002, the Doha Amendment (Kyoto Protocol Phase II) on $22^{\text {nd }}$ June 2015 and the Paris Agreement on $3^{\text {rd }}$ November 2016. The Government assigned the Ministry of Natural Resources and Environment to be the focal point of Vietnam to participate in and implement the UNFCCC, Kyoto Protocol and the Paris Agreement.

To create a legal basis for the implementation of the CDM, the Government of Vietnam has issued: 1) Directive No. 35/2005/CT-TTg dated $17^{\text {th }}$ October 2005 of the Prime Minister on the implementation Kyoto Protocol under the United Nations Framework Convention on Climate Change; 2) Decision No. 130/2007/QD-TTg dated $2^{\text {nd }}$ August 2007 of the Prime Minister on a number of financial mechanisms and policies for investment projects under the Clean Development Mechanism.

To create a legal corridor for domestic and foreign agencies, enterprises (state and private) to implement CDM activities, the Ministry of Natural Resources and Environment has issued Circular No. 15/2014/TT-BTNMT dated 24 ${ }^{\text {th }}$ March 2014 providing the formulation and grant of letter of endorsement and letter of approval for projects under the clean development mechanism within the Kyoto Protocol.

The Ministry of Finance and the Ministry of Natural Resources and Environment have issued 1) Joint Circular No. 58/2008/TTLT-BTC-BTNMT dated $4^{\text {th }}$ July 2008 guiding the implementation of a number of articles of Decision No. 130/2007/QD-TTg dated $2^{\text {nd }}$ August 2007 of the Prime Minister on a number of financial mechanisms and policies for investment projects under CDM; 2) Joint Circular No. 204/2010/TTLT-BTC-BTN \& MT dated 15th December 2010 amending and supplementing a number of contents of Joint Circular No. 58/2008/TTLT-BTC-BTNMT dated $4^{\text {th }}$ July 2008.

In order for a project to be registered and recognized as a CDM project and to be considered for a certified GHG emission reduction certificate being issued by the International Executive Committee on CDM (EB), project developers and implementers must ensure complying with national regulations and general international regulations on CDM.

\section{2) Policies related to MRV of mitigation actions}

One of the important tasks to operate the carbon market in the country is to develop a comprehensive and comprehensive MRV system to reduce emissions to the national, sectoral and sub-national levels. Vietnam has not yet had specific, unified guidelines and legal basis for the implementation of MRV in reducing GHG emission activities. MRV for mitigation actions should be developed based on the existing institutional arrangement as laid out under BUR preparation to avoid duplication of efforts and to streamline the process. Currently, there are a number of relevant legal documents that can be a good basis for the national MRV 
system in Vietnam, including:

The Prime Minister's Decision No. 2053/QD-TTg on promulgating the Plan to implement the Paris Agreement on Climate Change (Prime Minister, 2016). One of the key tasks mentioned in the Decision is to establish a national and sectoral transparency (MRV) system for GHG emissions mitigation, climate change adaptation and resource mobilization. In addition, the Third National Communication also proposed an MRV system for mitigation actions at the national level (MONRE, 2019).

The National GHG Inventory system was approved by Decision No. 2359/ QD-TTg of the Prime Minister in 2015 as one of the important legal foundation for the MRV system in Vietnam. One of the specific objectives of the National GHG Inventory system is to support for the MRV of NAMAs and mitigation targets set by Vietnam's NDC. The National GHG Inventory system also develops reporting templates so that line Ministries can submit their activity data in relevant sectors and it will be the input for the national GHG inventory. These reporting templates will be an important basis for measurement and reporting of mitigation actions.

Law on Energy Efficiency and Energy Efficiency issued on $28^{\text {th }}$ June 2010 regulates efficient use of energy; policies and solutions to promote energy efficiency; and rights, obligations and responsibilities of organizations, families and individuals to save energy. The Ministry of Industry and Trade (MOIT) is responsible for coordinating with relevant agencies on energy statistics to issue energy statistical indicators (Article 7) and collecting and managing energy data (Article 45). In addition, key energy users will be required to conduct energy audits every three years (Article 33). It can be said that the Law on Energy Saving and Efficiency is the basis for monitoring energy use activities and energy saving solutions (Prime Minister, 2011).

Decision No. 1775/QD-TTg dated 12 ${ }^{\text {th }}$ November 2012 regulates the Project on management of GHG emissions and management of carbon credit trading activities to the world market. The project also sets out targets for capacity building in national GHG inventories and building national MRV systems. At present, however, the specifics of MRV-related activities are still limited and insufficient to establish and establish a national MRV system (Prime Minister, 2012). Regarding MRV at local level, at present, the establishment of the MRV system at local level is being studied by local authorities. With support from SPI-NAMA project, Ho Chi Minh City has been the first to propose the development of an MRV system at city level and it is expected to start from 2019. This system is implemented in three steps: definition of mitigation actions for MRV implementation (Step 1); Implementation of MRV (Step 2); and Approval of MRV (Step 3). In terms of project level, for each type of project, a MRV system at project level will be developed by project stakeholders in accordance with the guideline of the mechanism. For CDM projects, the MRV system will be applied according to the guidelines of the CDM Executive Board. For JCM projects between Japan and Vietnam, 
the MRV system will be applied according to the Joint Committee's guidelines.

\subsection{Potential to Generate Carbon Credits}

On $24^{\text {th }}$ July 2020, the Prime Minister approved Vietnam's updated Nationally Determined Contribution (NDC) which sets the mitigation target of reducing the national GHG emissions by $9 \%$ compared to the Business-As-Usual scenario (BAU) by domestic resources, and the mitigation target can increase up to $27 \%$ if Vietnam receives international support. In the updated NDC, Vietnam has allocated mitigation targets to five sectors, particularly energy, agriculture, industrial processes (IP), land use, land use and forestry change (LULUCF) and waste in the period of 2021-2030 (MONRE, 2020) (Table 2 and Figure 1).

National GHG emission mitigation measures against BAU for the period 2021-2030 were identified for the energy, agriculture, LULUCF, waste and industrial processes sectors. Contribution to GHG emission reduction is determined by unconditional and conditional contributions through bilateral and multilateral cooperation and implementation of new mechanisms under the Agreement Paris.

Table 2. Mitigation targets by 2030 compared to BAU (MONRE, 2020).

\begin{tabular}{|c|c|c|c|c|c|c|}
\hline \multirow[b]{2}{*}{ Sector } & \multicolumn{2}{|c|}{ Unconditional contribution } & \multicolumn{2}{|c|}{ Conditional contribution } & \multicolumn{2}{|c|}{ Total contribution } \\
\hline & $\begin{array}{c}\text { Compare to } \\
\text { the national } \\
\text { BAU }(\%)\end{array}$ & $\begin{array}{l}\text { Emission } \\
\text { reduction } \\
\left(\mathrm{MtCO}_{2 \mathrm{e}}\right)\end{array}$ & $\begin{array}{c}\text { Compare to } \\
\text { the national } \\
\text { BAU }(\%)\end{array}$ & $\begin{array}{l}\text { Emission } \\
\text { reduction } \\
\left(\mathrm{MtCO}_{2 \mathrm{e}}\right)\end{array}$ & $\begin{array}{c}\text { Compare to } \\
\text { the national } \\
\text { BAU }(\%)\end{array}$ & $\begin{array}{l}\text { Emission } \\
\text { reduction } \\
\left(\mathrm{MtCO}_{2 \mathrm{e}}\right)\end{array}$ \\
\hline Energy & 5.5 & 51.5 & 11.2 & 104.3 & 16.7 & 155.8 \\
\hline Agriculture & 0.7 & 6.8 & 2.8 & 25.8 & 3.5 & 32.6 \\
\hline LULUCF* & 1.0 & 9.3 & 1.3 & 11.9 & 2.3 & 21.2 \\
\hline Waste & 1.0 & 9.1 & 2.6 & 24.0 & 3.6 & 33.1 \\
\hline IPPU & 0.8 & 7.2 & 0.1 & 0.8 & 0.9 & 8.0 \\
\hline Total & 9.0 & 83.9 & 18.0 & 166.8 & 27.0 & 250.8 \\
\hline
\end{tabular}

Note: *: increased removals. 


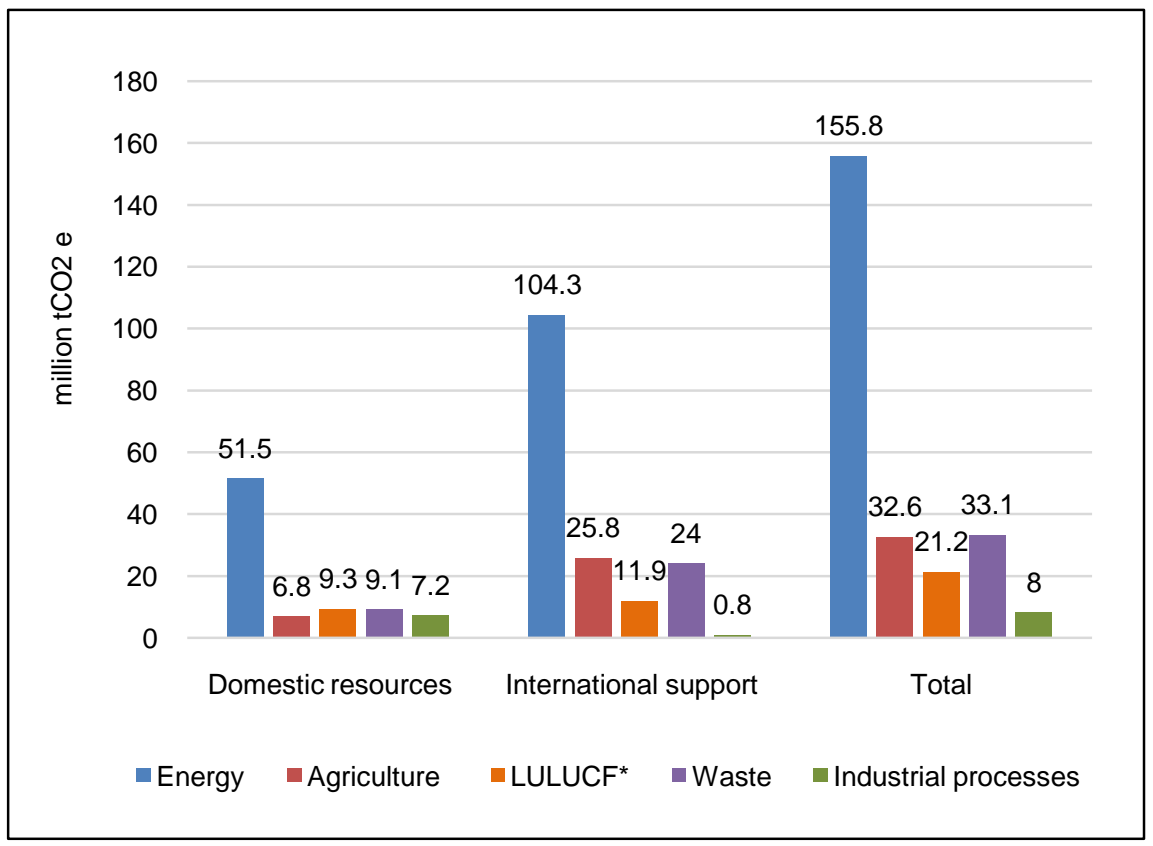

Figure 1. Mitigation potential of five sectors in case of unconditional and conditional contribution (MONRE, 2020).

With domestic resources, by 2030, Vietnam will reduce 9\% of total GHG emissions compared to the national BAU, equivalent to 83.9 million tons of $\mathrm{CO}_{2}$ eq. The estimated GHG emission mitigation in the energy sector is 51.5 million tons $\mathrm{CO}_{2} \mathrm{eq}$, accounting for $5.5 \%$ of the national BAU; the agricultural sector is 6.8 million tons of $\mathrm{CO}_{2} \mathrm{eq}$, accounting for $0.7 \%$ of the national BAU; LULUCF sector is 9.3 million tons of $\mathrm{CO}_{2} \mathrm{eq}$, accounting for $1.0 \%$ of the national BAU; Waste sector is 9.1 million tons $\mathrm{CO}_{2} \mathrm{e}$, accounting for $1.0 \%$ of the national BAU; IP sector is 7.2 million tons $\mathrm{CO}_{2} \mathrm{e}$, accounting for $0.8 \%$ of the national BAU. GHG reductions are estimated in each sector, but during implementation the updated NDC will be adjusted to the actual conditions to ensure the national contribution target is met.

The above-mentioned $9 \%$ contribution could be increased to $27 \%$ of the national BAU (equivalent to 250.8 million tons of $\mathrm{CO}_{2} \mathrm{eq}$ ) when Vietnam receives international support. It can be in the forms of bilateral, multilateral cooperation and implementation of mechanisms in the Paris Agreement on climate change. In which, GHG emission reduction in the energy sector is estimated at 155.8 million tons $\mathrm{CO}_{2}$ eq, accounting for $16.7 \%$ of the national $\mathrm{BAU}$; the agricultural sector is 32.6 million tons $\mathrm{CO}_{2} \mathrm{eq}$, accounting for $3.5 \%$ of the national BAU; in LULUCF sector is 21.2 million tons of $\mathrm{CO}_{2} \mathrm{eq}$, accounting for $2.3 \%$ of the national BAU; waste sector is 33.2 million tons $\mathrm{CO}_{2} \mathrm{eq}$, accounting for $3.6 \%$ of the national BAU; IP sector is 8.0 million tons of $\mathrm{CO}_{2} \mathrm{eq}$, accounting for $0.9 \%$ of the national BAU (MONRE, 2020). In addition, afforestation projects that increase GHG sequestration, CDM projects or nationally appropriate climate change mitigation actions (NAMAs), when implemented, will also create a Carbon credits to attract investment from domestic and foreign enterprises. 


\subsection{Vietnam's Experience in Preparedness and Development of Carbon Market}

\subsubsection{CDM}

As of June 2020, Vietnam had 257 CDM projects and 13 Program of Activities registered by the CDM Executive Board (EB). Vietnam ranks $4^{\text {th }}$ in the world in terms of number of projects, with a total potential GHG reduction of about 140 million tons of $\mathrm{CO}_{2}$ equivalent $\left(\mathrm{CO}_{2} \mathrm{eq}\right)$ during the crediting period. Out of 257 projects, energy projects account for $87.6 \%$, waste treatment $10.2 \%$, afforestation and reforestation for $0.4 \%$ and others $1.8 \%$. The number of Certified Emission Reductions (CERs) issued by EB so far is over 18 million, ranking $6^{\text {th }}$ in the world.

\subsubsection{Voluntary Market}

For the voluntary carbon market, the carbon market that is not under the framework of the Kyoto Protocol, Vietnam also has the potential to participate through mechanisms such as the JCM, VCS, GS and the REDD Program.

Vietnam joined the JCM scheme in July 2013 through a memorandum of understanding on "Low carbon growth and building a JCM joint credit mechanism". The purposes of the JCM Mechanism are: 1) Disseminate Japanese technologies, products, systems, services, and low-carbon infrastructure, contributing to sustainable development in developing countries; 2) Contribution of quantitative GHG emissions reduction through mitigation actions in developing countries and achievement of the emission reduction goals of developed countries (Japan); and 3) Contribution to the UNFCCC's goal of reducing global emissions.

Under this mechanism, when Japanese enterprises give consultancy and transfer energy saving and emission reduction technologies to Vietnamese enterprises, they will enjoy preferential credit from Japan. The maximum credit level will be up to $50 \%$ of the total project cost and the $\mathrm{CO}_{2}$ eq cut will be charged to the Japanese side.

During implementing the JCM Mechanism, the Japanese Government considers it as a tool to promote advanced low emission technology and development through JCM projects; mandatory implementation of measurement, verification report and application of approved methodology for GHG emission reduction activities. The JCM mechanism also generates non-commercial carbon credits that can contribute to the efforts of both Japan and Vietnam to implement international commitments on GHG mitigation. Under the JCM Mechanism, businesses can install low-carbon technology, acquire and disseminate professional knowledge. Property on a project implementation basis is wholly owned and managed by $\mathrm{Vi}$ etnam.

Following the direction of the Prime Minister in Official Dispatch No. 10728/VPCP-QHQT dated 19 ${ }^{\text {th }}$ December 2013 of the Office of the Government, the Ministry of Natural Resources and Environment has coordinated with relevant agencies to pilot the JCM. In order to promote the development and implementation of projects through JCM, Ministry of Natural Resources and Environment has 
issued Circular No. 17/2015/TT-BTNMT dated $6^{\text {th }}$ April 2015 stipulating the development and implementation of the JCM projects under the framework of cooperation between the governments of Vietnam and Japan on low-carbon growth. Up to now, the Vietnam-Japan Joint Committee has approved 15 methodologies for JCM projects, registered 14 projects and issued 4415 carbon credit for 8 projects.

Besides the implementation of projects through CDM and JCM mechanisms, there are number of GHG emission reduction projects in Vietnam registered under VCS and GS. Up to now, there are 17 projects registered under VCS with 603,417 carbon credit issued and 20 projects registered under the GS with 3,270,444 carbon credit issued.

Regarding the REDD mechanism, in 2005, in response to a joint proposal of the Governments of Papua New Guinea and Costa Rica, the $11^{\text {th }}$ Conference of the Parties to the Convention (COP11) of the UNFCCC was held to investigate the possibility of incorporating GHG emission reduction mechanisms through REDD efforts into the Kyoto Agreement. Realizing REDD's potential in reducing emissions, the Bali Action Plan was approved at COP13 in 2007. Vietnam is one of the nine countries participating in the United Nations Cooperation Program on REDD (UN-REDD) to get ready for REDD.

In general, in Vietnam, carbon trading mechanisms under the Kyoto Protocol (CDM) and outside the Kyoto Protocol (JCM, REDD+) have been established and implemented. These mechanisms will create supply and demand and will contribute to the formation of different types of carbon markets in Vietnam. In addition, in the context of international climate change negotiations and the implementation of the Paris Agreement on climate change with new emissions reduction commitments for the period 2021-2030, the demand for emissions trading and exchange GHGs will increase and the carbon market will become active again. The creation of a domestic carbon market will be a very good basis for Vietnam to achieve its commitment to reduce emissions and to be ready to attract climate change finance for domestic technological change. It is clear that in Vietnam, the current carbon market projects and studies are mainly focused on the orientation of preparedness for Vietnam to participate in the international carbon market.

\section{Conclusion}

This paper was supported by the National Science and Technology Program to respond to climate change and management of natural resources and the environment in the period of 2016-2020. The result of the paper will contribute to the first objective of the program, which is to effectively apply the advanced tools and models in reducing GHG emissions suitable to Vietnamese conditions.

From the above analysis, it can be seen that the demand for carbon credit trading in the world has become urgent and imperative after the Kyoto Protocol introduced the mandatory carbon market and market formation. Voluntary carbon schools with the need to submit and implement NDC, especially today, in the global climate change trend, is considered a fundamental and decisive factor for market operations in the world carbon market as well as the domestic carbon 
market. Some countries such as China, Thailand, and Korea have tested and operated with certain results. In Vietnam, the development of a carbon market will contribute to a number of achievements not only in the goal of reducing GHG emissions but also in taking advantage of financial opportunities for economic development, serving the goal of environmental protection and sustainable development of the country.

In Vietnam, during the development process, economic sectors still mainly use outdated technologies compared to those in other countries Therefore, the ability to improve technology to reduce GHG emissions is also very large, especially in both facilitating the carbon market and promoting investment with foreign enterprises. In addition, the Government is planning to transform the economic structure towards a sustainable direction and paying attention to the development of low-carbon economic sectors is also a beneficial factor for Vietnam's participation in the carbon market.

Thus, it can be seen that the development of a carbon market in Vietnam has great practical significance and it will contribute to helping Vietnam and the world achieve the goal of reducing GHG. Besides, it will take advantage of the mobilization of international, domestic, businesses, and private investors in this field as well as achieving the goal of environmental protection and sustainable development. However, in order for the carbon market to work effectively, it is necessary to focus on a number of points. It is recommended that it is necessary to develop a system of policies and mechanisms to support the development of the carbon market. Another point is that it is important to identify specific sectors/sectors that have the potential to generate carbon credits and make it easier to set up an MRV system for businesses to reduce emissions and create a co-benefit mechanism for domestic carbon market participants.

The assessment was implemented based on the assumption that all criteria have the same weights. Therefore, further studies are needed to evaluate the weight of each criterion to the potential of Vietnam to participate in the carbon market.

\section{Acknowledgements}

In Section 3.2. "Potential to generate carbon credits" has reflected the results of the national-level project title "Study to propose the design of carbon market in Vietnam", grant number: BDKH.40/16-20. The authors gratefully acknowledge the financial support from the National Science and Technology Program to respond to climate change, manage natural resources and the environment in the period 2016-2020.

\section{Conflicts of Interest}

The authors declare no conflicts of interest regarding the publication of this paper.

\section{References}

Böhm, S., \& Dabhi, S. (Eds.). (2009). Upsetting the Offset: The Political Economy of Car- 
bon Markets. London: Mayfly Books.

Boyd, E., Hultman, N. E., Roberts, T., Corbera, E., Ebeling, J., Liverman, D. M., Brown, K., Tippmann, R., Cole, J., Mann, P., Kaiser, M., Robbins, M., Bumpus, A., Shaw, A., Ferreira, E., Bozmoski, A., Villiers, C., \& Avis, J. (2007). The Clean Development Mechanism: An Assessment of Current Practice and Future Approaches for Policy. Tyndall Centre Working Paper 114. Environmental Change Institute, Oxford and Tyndall Centre for Climate Change Research, UK.

Bumpus, A., Murray, G., \& Liverman, D. M. (2009). Accumulation by Decarbonization and the Governance of Carbon Offsets. Economic Geography, 84, 127-155. https://www.jstor.org/stable/30033170 https://doi.org/10.1111/j.1944-8287.2008.tb00401.x

Ecosystem Marketplace (2019). Financing Emissions Reductions for the Future-State of the Voluntary Carbon Markets Report 2019.

Ellerman, A. D., Convery, F. J., \& de Perthuis, C. (2010). Pricing Carbon: The European Union Emissions Trading Scheme. Cambridge : Cambridge University Press.

European Commission (EC) (2016). Factsheet on the EU Emissions Trading System (EU ETS).

IETA (2016). A Vision for the Market Provisions of the Paris Agreement. Geneve, Switzerland.

International Carbon Action Partnership (ICAP) (2020). China National ETS. https://icapcarbonaction.com/en/?option=com_etsmap\&task=export\&format=pdf\&layout $=$ list\&systems $\% 5 \mathrm{~B} \% 5 \mathrm{D}=55$

Marcu, A. (2016). Carbon Market Provisions in the Paris Agreement (Article 6). CRPS Special Report.

Marron, D. B., Toder, E. J., \& Austin, L. (2015). Taxing Carbon: What, Why, and How. Washington D.C.: Tax Policy Center. https://doi.org/10.2139/ssrn.2625084

Michaelowa, A. (2005). Determination of Baselines and Additionality for the CDM: A Crucial Element of Credibility of the Climate Regime. In F. Yamin (Ed.), Climate Change and Carbon Markets: A Handbook for Emissions Reduction Mechanisms (pp. 305-320). London: Earthscan.

Ministry of Natural Resources and Environment (MONRE) (2019). Third National Communication of Vietnam to UNFCCC. Ha Noi, Vietnam.

Ministry of Natural Resources and Environment (MONRE) (2020). Technical Report on Vietnam's Updated Nationally Determined Contribution of Vietnam. Ha Noi, Vietnam.

Pearson, B., \& Shao Loong, Y. (2003). The CDM: Reducing Greenhouse Gas Emissions or Relabeling Business as Usual? Third World Network, CDM Watch.

Prime Minister (2011). Decision No. 2139/QD-TTg Dated December $5^{\text {th }}, 2011$ of the Prime Minister approving the National Climate Change Strategy.

Prime Minister (2012). Decision No. 1775/QD-TTg dated November 21 $1^{\text {st }}, 2012$ of the Prime Minister Approving the Plan on Greenhouse Gas Emissions Management; Management of Carbon Trading Activities to the World Markets.

Prime Minister (2016). Decision No. 2053/QD-TTg Dated October $28^{\text {th }}, 2016$ of the Prime Minister Approving the Implementation Plan of Paris Agreement in Vietnam.

Richard, G. N., William, A. P., \& Daniel, R. (2012). Carbon Markets: Past, Present and Future. Resources for the Future Discussion Paper No. 12-51 https://papers.ssrn.com/sol3/papers.cfm?abstract_id=2188930

Schneider, L. (2007). Is the CDM Fulfilling Its Environmental and Sustainable Development Objectives? An Evaluation of the CDM and Options for Improvement. Berlin: Öko-Institut.

Smith, K. (2007). The Carbon Neutral Myth Offset Indulgences for your Climate Sins. The Netherlands: Transnational Institute, Imprenta Hija de J. Prats Bernadás.

Soroos, M. S. (2001). Global Climate Change and the Futility of the Kyoto Process. Global Environmental Politics, 1, 1-9. https://doi.org/10.1162/152638001750336541

Woerdman, E. (2000). Implementing the Kyoto Protocol: Why JI and CDM Show More Promise than International Emissions Trading. Energy Policy, 28, 29-38. https://doi.org/10.1016/S0301-4215(99)00094-4 
M. K. Lien et al.

World Bank, Ecofys and Vivid Economics (2016). State and Trends of Carbon Pricing. Washington, D.C.: World Bank.

WWF (2008). EU ETS Phase II-The Potential and Scale of Windfall Profits in the Power Sector.

http://assets.panda.org/downloads/point_carbon_wwf_windfall_profits_mar08_final_rep ort_1.pdf 